\title{
Effect of Sheet Size and Atomic Structure on the Antibacterial Activity of Nb- MXene Nanosheets
}

Ravi P. Pandey, ${ }^{\mathrm{a}, \#}$ P. Abdul Rasheed, ${ }^{\mathrm{a}, \mathrm{b}, \#}$ Tricia Gomez, ${ }^{\mathrm{a}}$ Kashif Rasool, ${ }^{\mathrm{a}}$ Janarthanan Ponraj, ${ }^{\mathrm{a}}$ Kaitlyn Prenger, ${ }^{\mathrm{c}}$ Michael Naguib, ${ }^{\mathrm{c}}$ and Khaled A Mahmoud*a

${ }^{a}$ Qatar Environment and Energy Research Institute, Hamad Bin Khalifa University, Qatar Foundation, P.O. Box 34110, Doha, Qatar

${ }^{b}$ Department of Biomedical Engineering, Saveetha Engineering College, Saveetha Nagar, Chennai -602 105, India

${ }^{c}$ Department of Physics and Engineering Physics, Tulane University, New Orleans, LA 70118, USA

E-mail:kmahmoud@hbku.edu.qa; Phone:+974 4454 1694, fax:+974 44541528

\# These authors contributed equally to this work 


\section{Supporting Information}
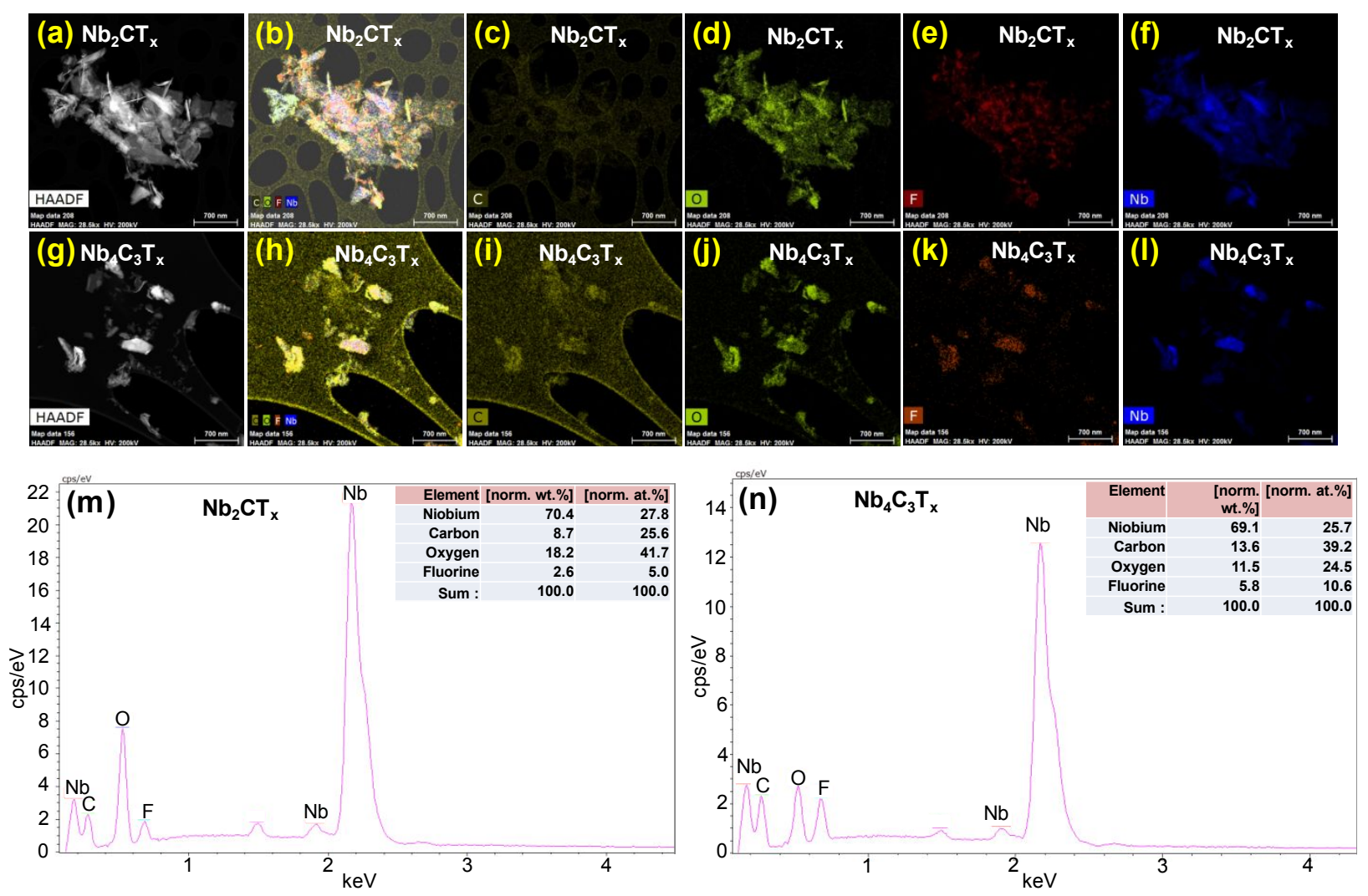

Fig. S1. Energy dispersive spectroscopy (EDS) elemental mapping and EDS spectra. (a) high angular annular dark field (HAADF)-scanning transmission electron microscopy (STEM) images of $\mathrm{Nb}_{2} \mathrm{CT}_{\mathrm{x}}$, (b) mixed elemental mapping of $\mathrm{Nb}_{2} \mathrm{CT}_{\mathrm{x}}$, (c) carbon mapping of $\mathrm{Nb}_{2} \mathrm{CT}_{\mathrm{x}}$, (d) oxygen mapping of $\mathrm{Nb}_{2} \mathrm{CT}_{\mathrm{x}}$, (e) fluorine mapping of $\mathrm{Nb}_{2} \mathrm{CT}_{\mathrm{x}}$, (f) niobium mapping of $\mathrm{Nb}_{2} \mathrm{CT}_{\mathrm{x}},(\mathrm{g})$ HAADF-STEM images of $\mathrm{Nb}_{4} \mathrm{C}_{3} \mathrm{~T}_{\mathrm{x}}$, (h) mixed elemental mapping of $\mathrm{Nb}_{4} \mathrm{C}_{3} \mathrm{~T}_{\mathrm{x}}$, (i) carbon mapping in $\mathrm{Nb}_{4} \mathrm{C}_{3} \mathrm{~T}_{\mathrm{x}}$, (j) oxygen mapping of $\mathrm{Nb}_{4} \mathrm{C}_{3} \mathrm{~T}_{\mathrm{x}}$, (k) fluorine mapping of $\mathrm{Nb}_{4} \mathrm{C}_{3} \mathrm{~T}_{\mathrm{x}}$, (l) niobium mapping of $\mathrm{Nb}_{4} \mathrm{C}_{3} \mathrm{~T}_{\mathrm{x}},(\mathrm{m})$ EDS spectrum of $\mathrm{Nb}_{2} \mathrm{CT}_{\mathrm{x}}$ and (n) EDS spectrum of $\mathrm{Nb}_{4} \mathrm{C}_{3} \mathrm{~T}_{\mathrm{x}}$. 
(a)

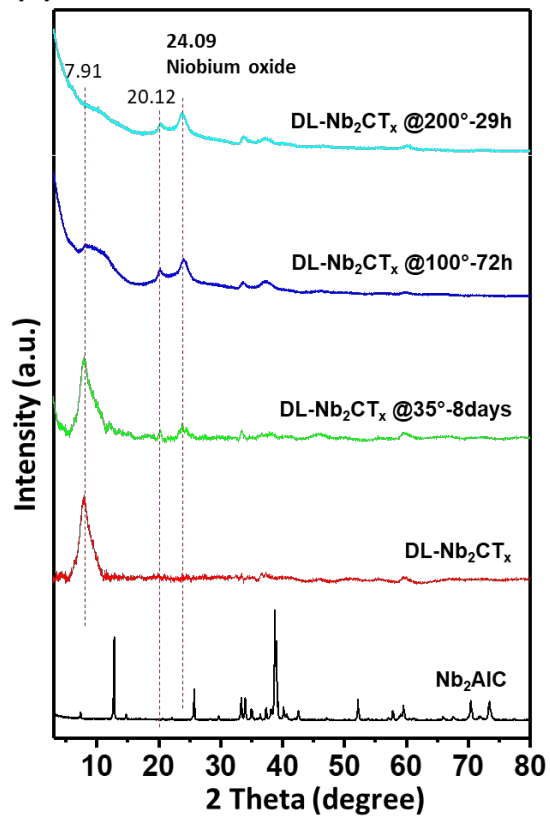

(b)

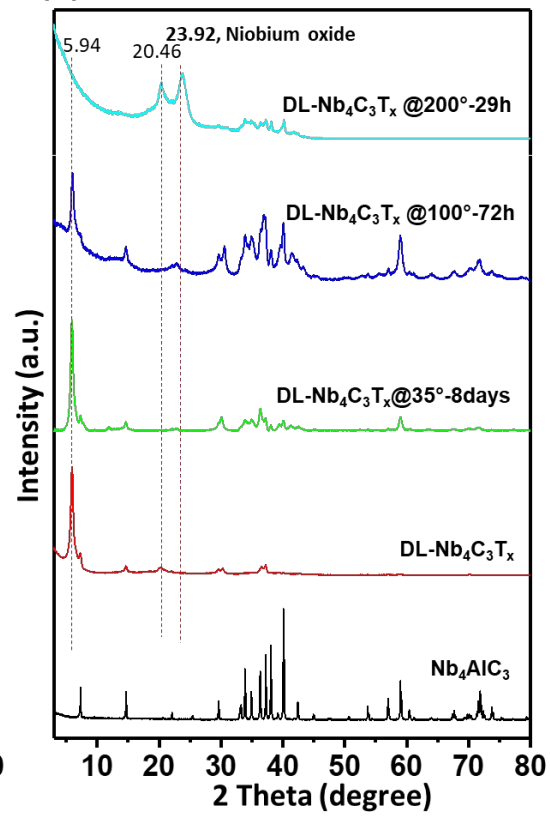

(c)

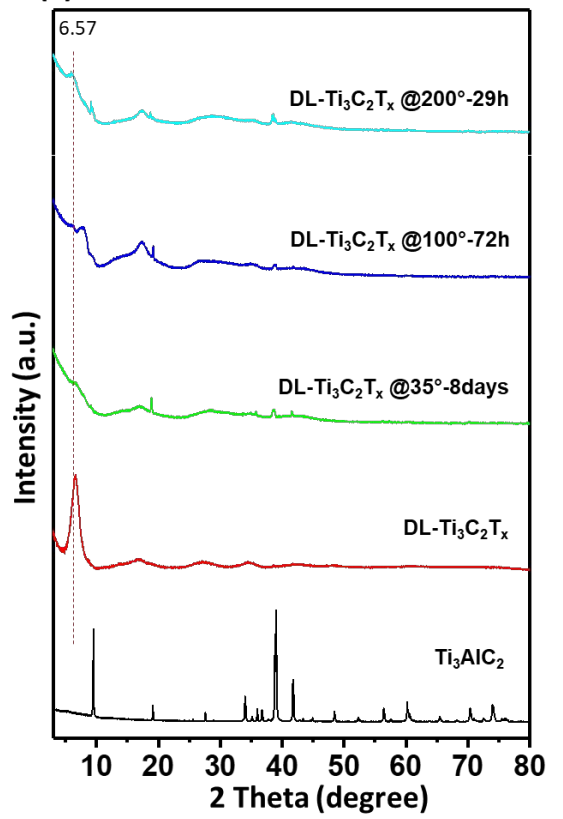

Fig. S2. Powder XRD pattern of (a) DL-Nb $\mathrm{CT}_{\mathrm{x}}$ (b) DL-Nb $\mathrm{C}_{3} \mathrm{~T}_{\mathrm{x}}$ and (c) DL- $\mathrm{Ti}_{3} \mathrm{C}_{2} \mathrm{~T}_{\mathrm{x}}$ before and after thermal treatments. 

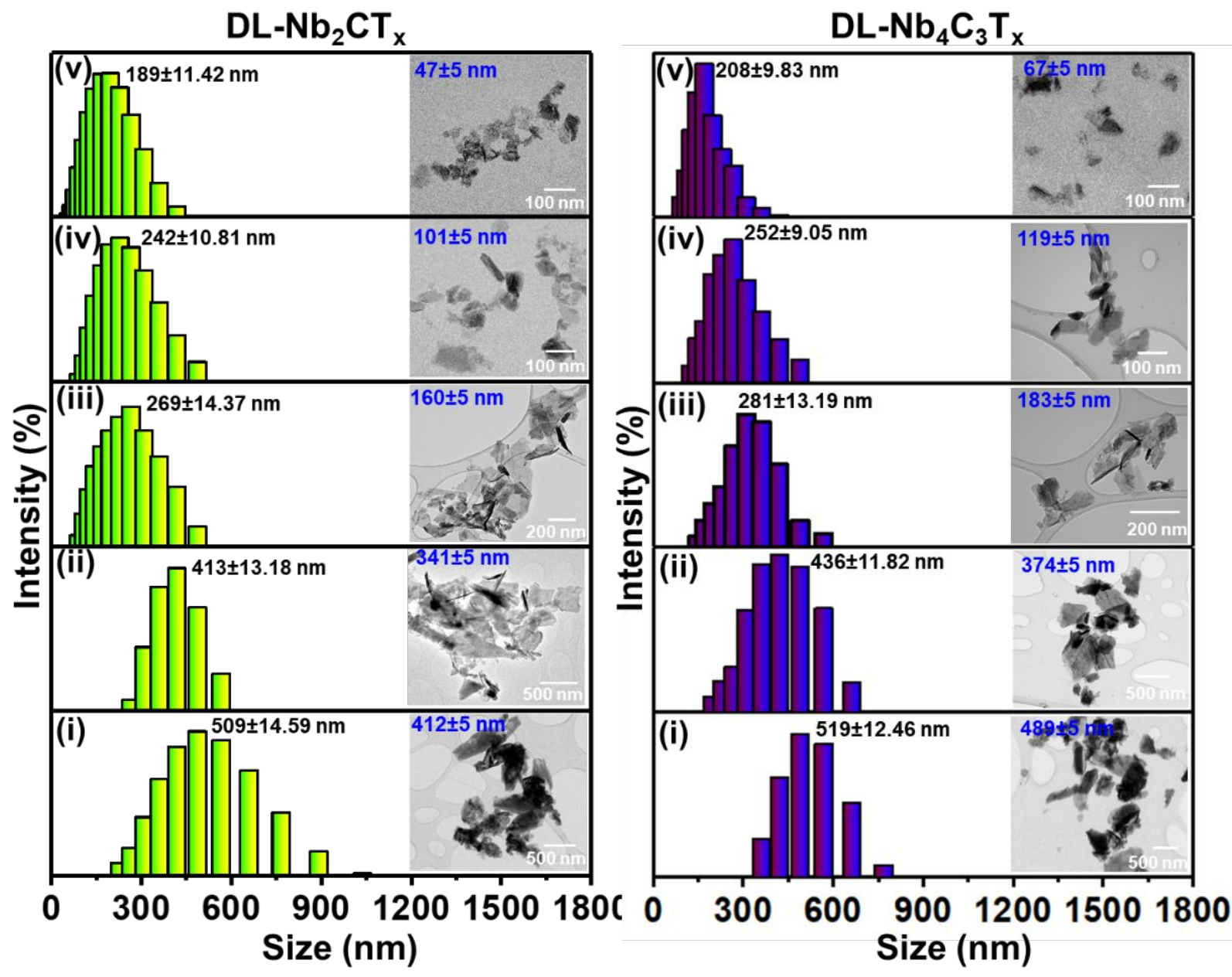

Fig. S3. Size distributions of DL-Nb $\mathrm{CT}_{\mathrm{x}}$ and $\mathrm{DL}-\mathrm{Nb}_{4} \mathrm{C}_{3} \mathrm{~T}_{\mathrm{x}} \mathrm{MXenes}$ ultra-probe sonication for (i) $40 \mathrm{~min}$, (ii) $60 \mathrm{~min}$, (iii) $80 \mathrm{~min}$, (iv) $100 \mathrm{~min}$, and (v) $120 \mathrm{~min}$. Inserts show their representative TEM images and lateral sizes.

Fig. S4 shows the zone of inhibition of ML-Nb $\mathrm{CT}_{\mathrm{x}}, \mathrm{DL}-\mathrm{Nb}_{2} \mathrm{CT}_{\mathrm{x}}, \mathrm{ML}-\mathrm{Nb}_{4} \mathrm{C}_{2} \mathrm{~T}_{\mathrm{x}}$ and $\mathrm{DL}-\mathrm{Nb}_{4} \mathrm{C}_{3} \mathrm{~T}_{\mathrm{x}}$ MXenes against $E$. coli and $S$. aureus cells. The inhibition of bacterial growth was maximum in the area directly surrounding MXene. The diameter of the inhibition zone against E. coli was 11 $\mathrm{mm}, 18 \mathrm{~mm}, 14 \mathrm{~mm}$ and $19 \mathrm{~mm}$, whereas, it was $6 \mathrm{~mm}, 9 \mathrm{~mm}, 8 \mathrm{~mm}$ and $9 \mathrm{~mm}$ against $S$. aureus for $\mathrm{ML}-\mathrm{Nb}_{2} \mathrm{CT}_{\mathrm{x}}, \mathrm{DL}-\mathrm{Nb}_{2} \mathrm{CT}_{\mathrm{x}}, \mathrm{ML}-\mathrm{Nb}_{4} \mathrm{C}_{3} \mathrm{~T}_{\mathrm{x}}$, and $\mathrm{DL}-\mathrm{Nb}_{4} \mathrm{C}_{3} \mathrm{~T}_{\mathrm{x}}$, respectively. Both MXenes show 
inhibition zone against $E$. coli and $S$. aureus, however, the $\mathrm{DL}-\mathrm{Nb}_{2} \mathrm{CT}_{\mathrm{x}}$ and DL-Nb ${ }_{4} \mathrm{C}_{3} \mathrm{~T}_{\mathrm{x}}$ MXenes have a higher zone of inhibition than ML- $\mathrm{Nb}_{2} \mathrm{CT}_{\mathrm{x}}$ and ML-Nb${ }_{4} \mathrm{C}_{2} \mathrm{~T}_{\mathrm{x}}$ MXenes.

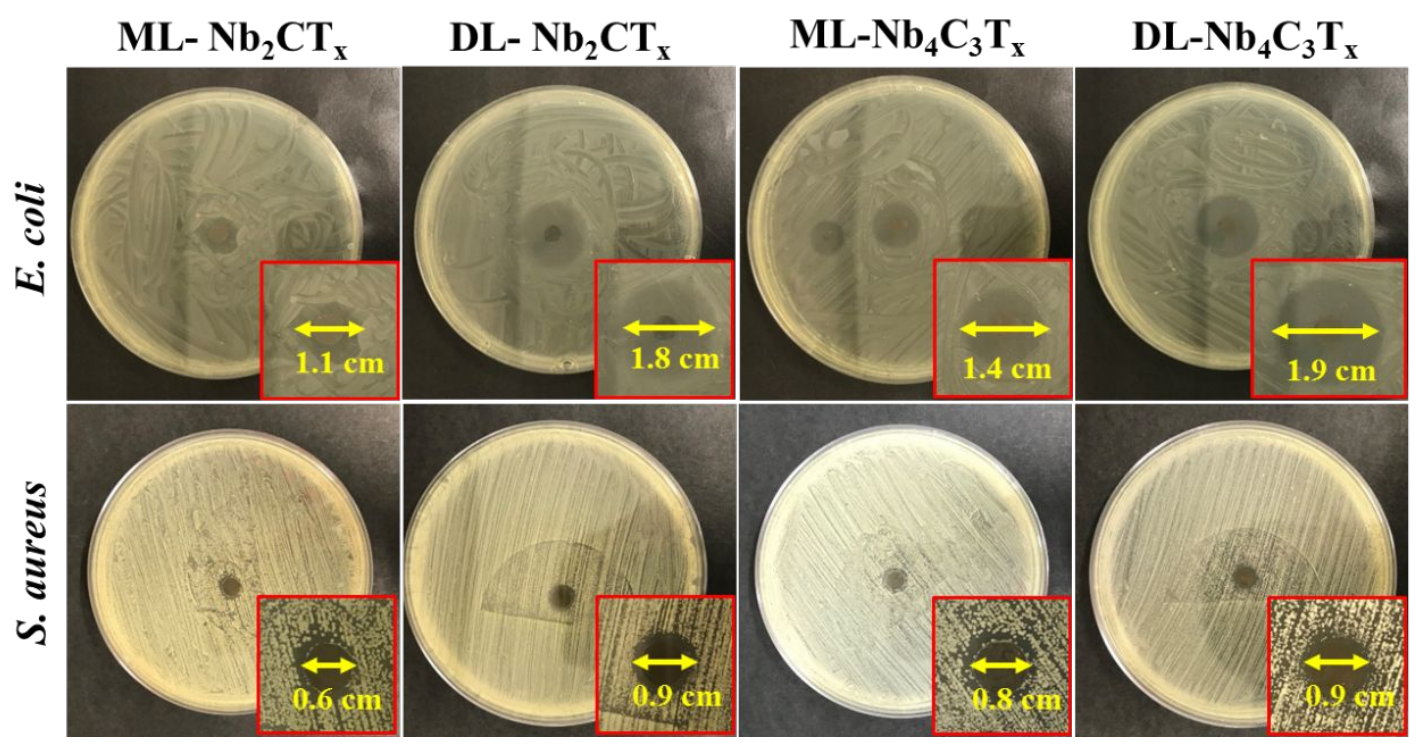

Fig. S4. Zone of inhibition of ML-Nb $\mathrm{CT}_{\mathrm{x}}, \mathrm{DL}-\mathrm{Nb}_{2} \mathrm{CT} \mathrm{T}_{\mathrm{x}}, \mathrm{ML}-\mathrm{Nb}_{4} \mathrm{C}_{2} \mathrm{~T}_{\mathrm{x}}$ and DL-Nb ${ }_{4} \mathrm{C}_{3} \mathrm{~T}_{\mathrm{x}}$ MXenes against $E$. coli and $S$. aureus.

The effect of incubation time on the growth inhibition of bacterial cell exposed to $100 \mu \mathrm{g} / \mathrm{mL}$ of DL- $\mathrm{Nb}_{2} \mathrm{CT}_{\mathrm{x}}-160$ and $\mathrm{DL}-\mathrm{Nb}_{4} \mathrm{C}_{3} \mathrm{~T}_{\mathrm{x}}-183$ was evaluated by varying the incubation time from 0 to 5 h. Fig. S5 shows the photographs of the agar plates onto which E. coli and S. aureus are grown after exposure to $\mathrm{DL}-\mathrm{Nb}_{2} \mathrm{CT}_{\mathrm{x}}-160$ and $\mathrm{DL}-\mathrm{Nb}_{4} \mathrm{C}_{3} \mathrm{~T}_{\mathrm{x}}-183$ at different incubation times and corresponding cell viabilities. The bacterial cell viability reduction increased with increasing incubation time and reached almost $85 \%$ at $3 \mathrm{~h}$ of incubation for both E. coli and $S$. aureus, after which, no significant effect was observed for both E. coli and S. aureus. Based on these results, 3 $\mathrm{h}$ was selected as the optimum incubation time for the subsequent experiments. 

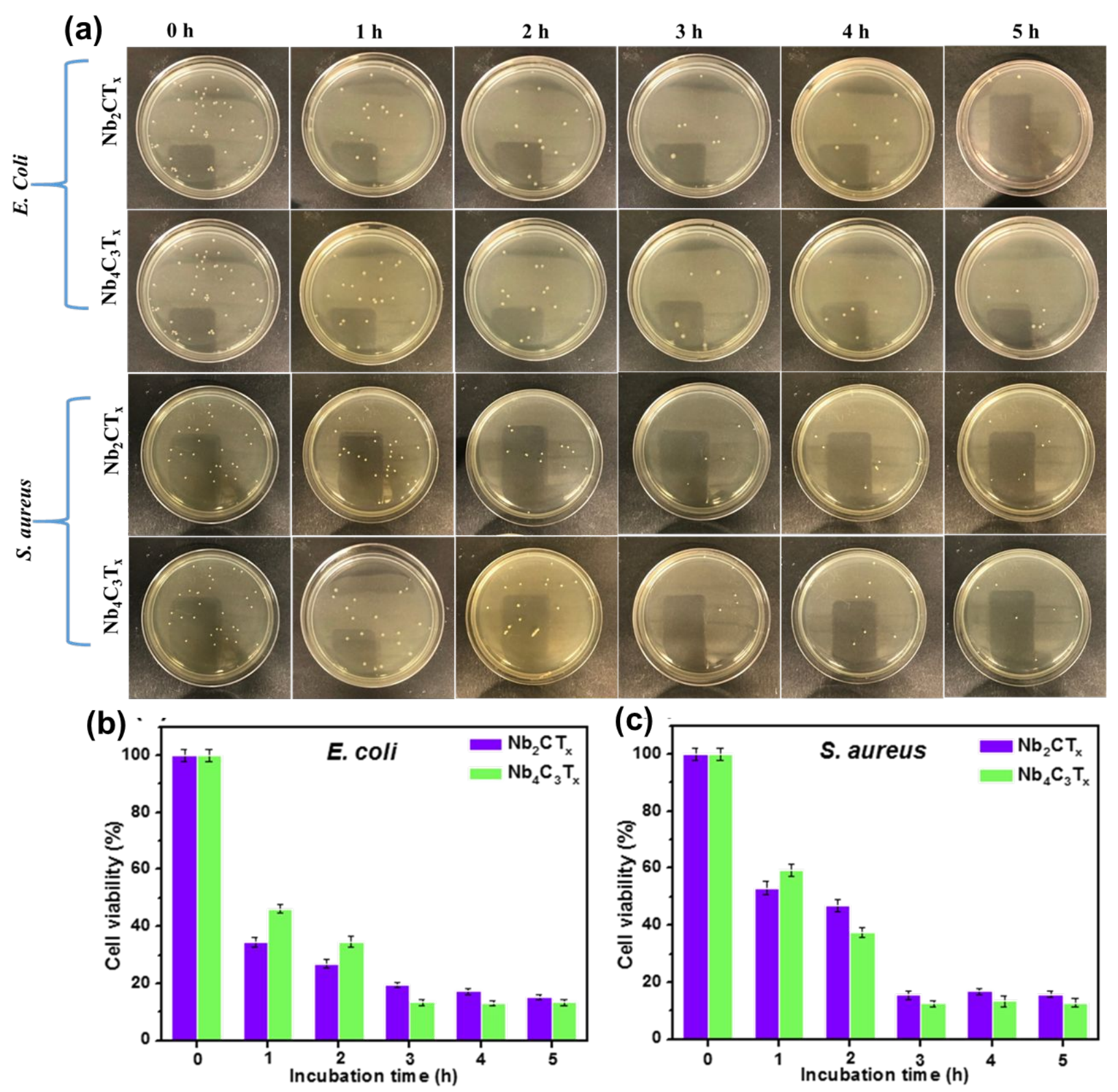

Fig. S5 (a) Photographs of agar plates onto which E. coli and S. aureus bacterial cells were recultivated after treatment with $100 \mu \mathrm{g} / \mathrm{mL}$ of $\mathrm{DL}-\mathrm{Nb}_{2} \mathrm{CT}_{\mathrm{x}}-160$ and $\mathrm{DL}-\mathrm{Nb}_{4} \mathrm{C}_{3} \mathrm{~T}_{\mathrm{x}}-183$ for 0 to $5 \mathrm{~h}$ incubation time, (b) cell viability measurements of E. coli and (c) cell viability measurements of 
S. aureus. Experiments were performed in triplicate and obtained similar results from three repeated measurements.” Bars display mean \pm S.D.

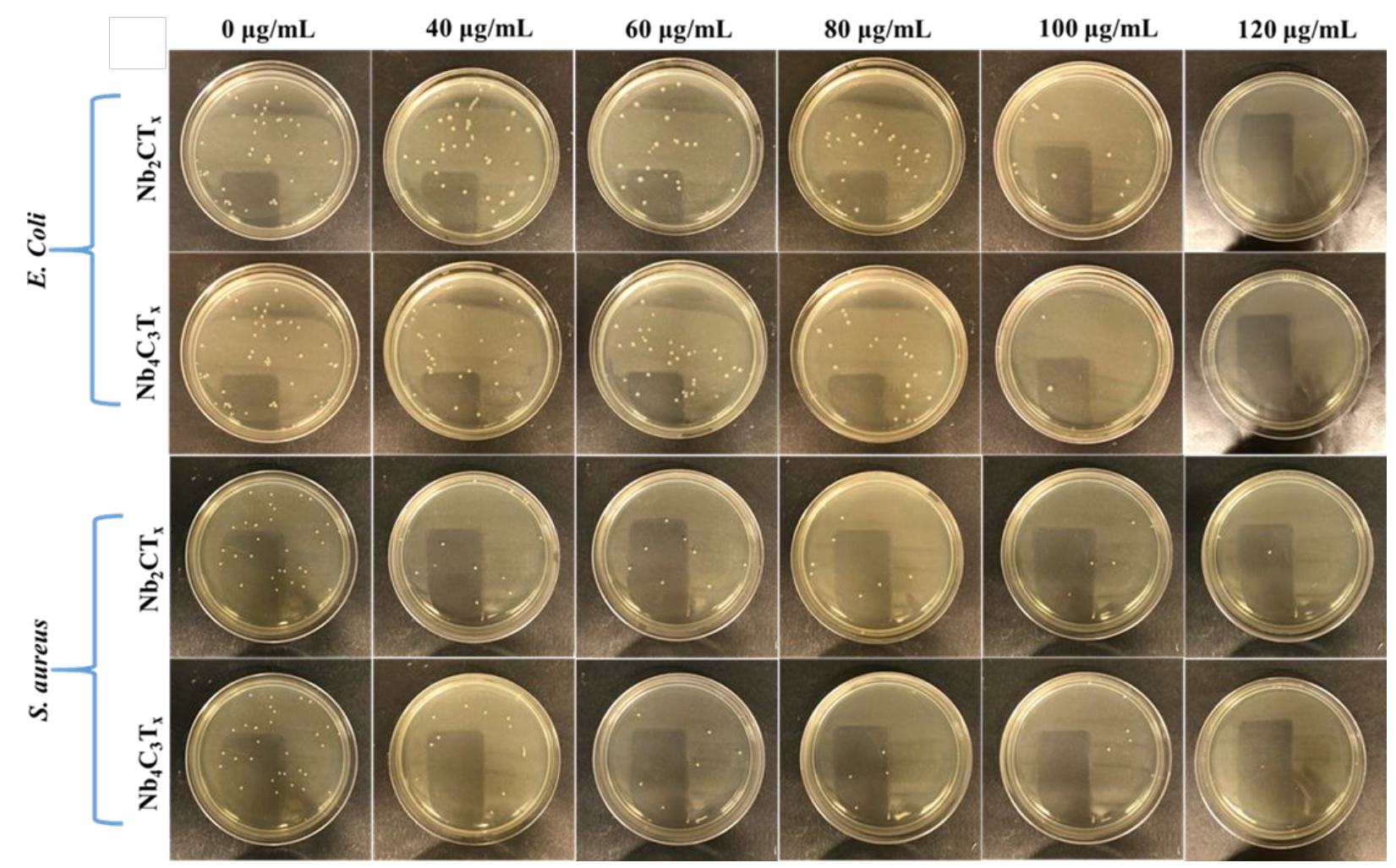

Fig. S6. Photographs of agar plates onto which E. coli and S. aureus bacterial cells were re-cultured after treatment for $3 \mathrm{~h}$ with different concentrations of DL- $\mathrm{Nb}_{2} \mathrm{CT}_{\mathrm{x}}-160$ and DL-Nb $\mathrm{C}_{3} \mathrm{~T}_{\mathrm{x}}-183$. 


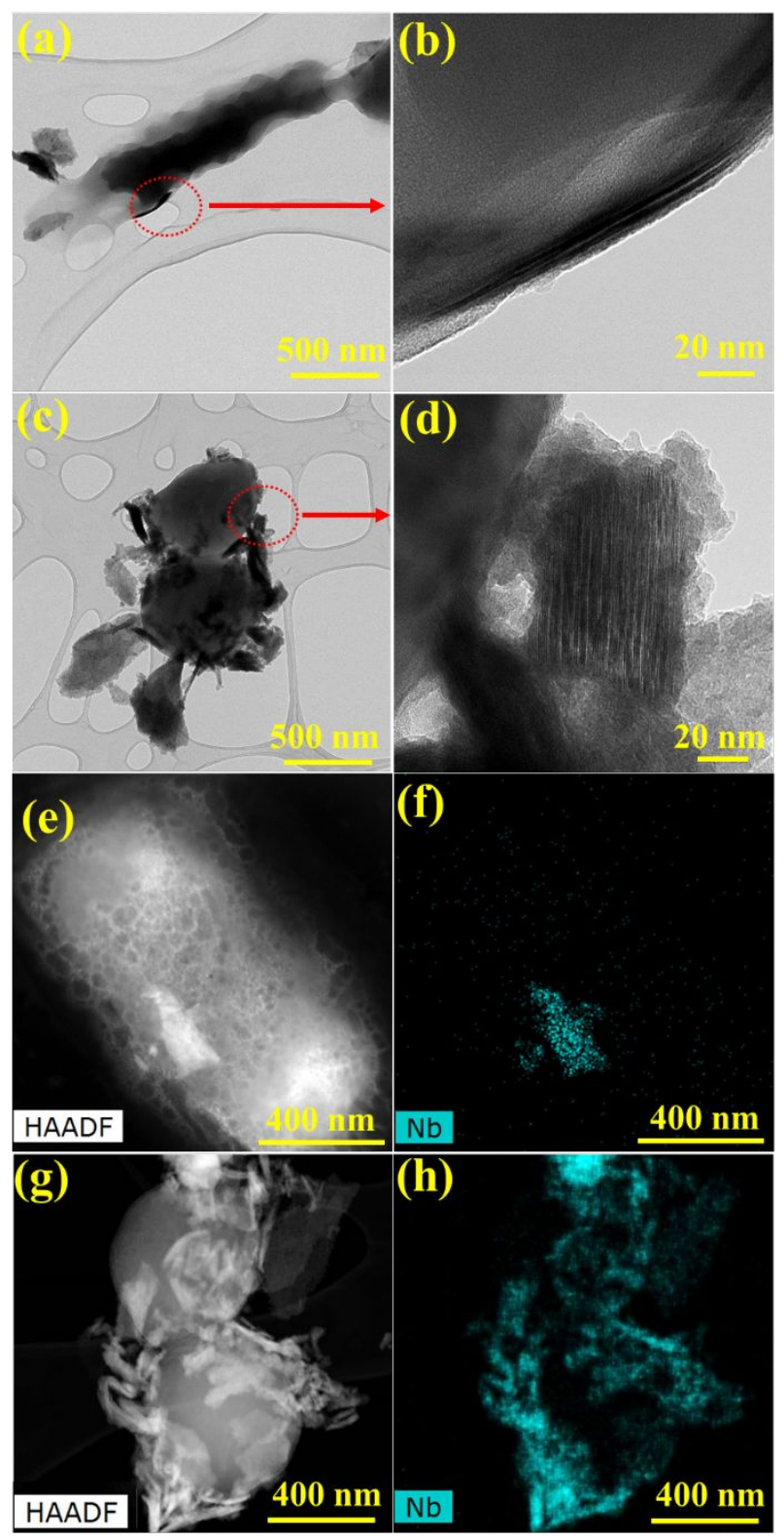

Fig. S7. TEM image of $E$. coli treated with DL-Nb $\mathrm{C}_{3} \mathrm{~T}_{\mathrm{x}}-183$ (a) low-resolution TEM, (b) highresolution TEM. TEM image of $S$. aureus treated with $\mathrm{DL}-\mathrm{Nb}_{4} \mathrm{C}_{3} \mathrm{~T}_{\mathrm{x}}-183$ (c) low-resolution TEM, (d) high-resolution TEM. (e) HAADF image of $E$. coli treated with DL-Nb $\mathrm{C}_{3} \mathrm{~T}_{\mathrm{x}}-183$, (f) elemental mapping of $E$. coli treated with DL-Nb $\mathrm{C}_{3} \mathrm{~T}_{\mathrm{x}}-183$, (g) HAADF image of $S$. aureus treated with DL- $\mathrm{Nb}_{4} \mathrm{C}_{3} \mathrm{~T}_{\mathrm{x}}-183$, and (h) elemental mapping of $S$. aureus treated with $\mathrm{DL}-\mathrm{Nb}_{4} \mathrm{C}_{3} \mathrm{~T}_{\mathrm{x}}-183$. 
Table S1: Antibacterial efficiency of different 2D MXene and graphene oxide materials

\begin{tabular}{|c|c|c|c|c|c|c|}
\hline \multirow[t]{2}{*}{ Material } & \multirow{2}{*}{$\begin{array}{l}\text { Concentrat } \\
\text { ion }\end{array}$} & \multicolumn{4}{|c|}{ Antibacterial Activity } & \multirow[t]{2}{*}{ Ref } \\
\hline & & $\begin{array}{l}\text { Bacterial } \\
\text { species }\end{array}$ & Incubation method & $\begin{array}{l}\text { Incubation } \\
\text { time (h) }\end{array}$ & $\begin{array}{l}\text { Inhibition } \\
(\%)\end{array}$ & \\
\hline $\begin{array}{l}\mathrm{Ti}_{3} \mathrm{C}_{2} \mathrm{~T}_{\mathrm{x}} \text { MXene } \\
\text { Nanosheets }\end{array}$ & $200 \mu \mathrm{g} / \mathrm{mL}$ & $\begin{array}{l}\text { E. coli }(-) \\
\text { B. subtilis }(+)\end{array}$ & $\begin{array}{l}\text { Bacterial Growth } \\
\text { Curves (optical } \\
\text { density), Colony } \\
\text { growth on agar plates } \\
\text { (colony counting) }\end{array}$ & $4 \mathrm{~h}$ & $98 \%$ & 1 \\
\hline Graphene oxide & $200 \mu \mathrm{g} / \mathrm{mL}$ & $\begin{array}{l}\text { E. coli }(-) \\
\text { B. subtilis }(+)\end{array}$ & $\begin{array}{l}\text { Bacterial Growth } \\
\text { Curves (optical } \\
\text { density), Colony } \\
\text { growth on agar plates } \\
\text { (colony counting) }\end{array}$ & $4 \mathrm{~h}$ & $90 \%$ & 1 \\
\hline
\end{tabular}

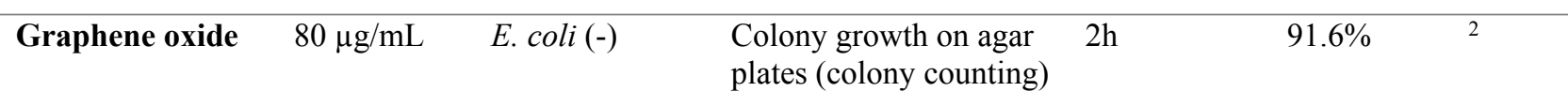

\begin{tabular}{|c|c|c|c|c|c|c|}
\hline $\begin{array}{l}\text { Reduced } \\
\text { Graphene oxide }\end{array}$ & $80 \mu \mathrm{g} / \mathrm{mL}$ & E. coli $(-)$ & $\begin{array}{l}\text { Colony growth on agar } \\
\text { plates (colony counting) }\end{array}$ & $2 \mathrm{~h}$ & $76.8 \%$ & 2 \\
\hline $\begin{array}{l}\mathrm{Ti}_{3} \mathrm{C}_{2} \mathrm{~T}_{z} / \mathrm{CS} \\
\text { fibers }\end{array}$ & $\begin{array}{l}0.75 \mathrm{wt}^{\%} \% \\
\mathrm{Ti}_{3} \mathrm{C}_{2} \mathrm{~T}_{\mathrm{z}}\end{array}$ & $\begin{array}{l}\text { E. } \operatorname{coli}(-) \\
\text { S. aureus }(+)\end{array}$ & $\begin{array}{l}\text { Colony growth on agar } \\
\text { plates (colony counting) }\end{array}$ & $4 \mathrm{~h}$ & $\begin{array}{l}95 \% \\
(\text { E.coli }) \\
62 \% \\
\text { aureus })\end{array}$ & 3 \\
\hline$M o S_{2} / T i_{3} C_{2} T_{x}$ & $100 \mu \mathrm{g} / \mathrm{mL}$ & $\begin{array}{l}\text { E. coli }(-) \\
\text { B. subtilis }(+)\end{array}$ & $\begin{array}{l}\text { Flow cytometry and } \\
\text { fluorescence imaging } \\
\text { with Propidium iodide }\end{array}$ & $3 \mathrm{~h}$ & $\begin{array}{l}\sim 15 \% \\
(\text { E.coli }) \\
20 \%(B . \\
\text { subtilis })\end{array}$ & 4 \\
\hline $\mathrm{Ti}_{2} \mathrm{C}$ MXene & $\mathrm{n} / \mathrm{a}$ & $\begin{array}{l}\text { Bacillus sp. }(+) \\
\text { S. aureus }(+) \\
\text { Sarcina }(+)\end{array}$ & $\begin{array}{l}\text { Agar diffusion method } \\
\text { (zone of inhibition) }\end{array}$ & $48 \mathrm{~h}$ & $\sim 0 \%$ & 5 \\
\hline 21\%Ag@MXene & $\mathrm{n} / \mathrm{a}$ & E. $\operatorname{coli}(-)$ & $\begin{array}{l}\text { Membrane filtration } \\
\text { Colony growth on } \\
\text { membrane filters } \\
\text { (colony counting) }\end{array}$ & $24 \mathrm{~h}$ & $99 \%$ & 6 \\
\hline $\mathrm{Nb}_{2} \mathrm{CT}_{\mathrm{x}}$ & $120 \mu \mathrm{g} / \mathrm{mL}$ & $\begin{array}{l}\text { E. coli }(-) \\
\text { S. aureus }(+)\end{array}$ & $\begin{array}{l}\text { Colony growth on agar } \\
\text { plates (colony counting) }\end{array}$ & $3 \mathrm{~h}$ & $\begin{array}{l}94 \% \\
(\text { E. coli) }\end{array}$ & $\begin{array}{l}\text { This } \\
\text { work }\end{array}$ \\
\hline
\end{tabular}


$92 \%$

(S.aureus)

\begin{tabular}{lllllll}
\hline & $120 \mu \mathrm{g} / \mathrm{mL}$ & E. coli $(-)$ & $\begin{array}{l}\text { Colony growth on agar } \\
\text { plates (colony counting) }\end{array}$ & $3 \mathrm{~h}$ & $96 \%$ & This \\
$\mathbf{N b}_{\mathbf{4}} \mathbf{C}_{\mathbf{3}} \mathbf{T}_{\mathbf{x}}$ & & S. aureus $(+)$ & & (E. coli) & work
\end{tabular}

$94 \%$

(S.aureus) 


\section{References}

(1) Rasool, K.; Helal, M.; Ali, A.; Ren, C. E.; Gogotsi, Y.; Mahmoud, K. A. Antibacterial Activity of Ti3C2Tx MXene. ACS Nano 2016, 10 (3), 3674-3684, DOI: 10.1021/acsnano.6b00181.

(2) Liu, S.; Zeng, T. H.; Hofmann, M.; Burcombe, E.; Wei, J.; Jiang, R.; Kong, J.; Chen, Y. Antibacterial Activity of Graphite, Graphite Oxide, Graphene Oxide, and Reduced Graphene Oxide: Membrane and Oxidative Stress. ACS Nano 2011, 5 (9), 6971-6980, DOI: 10.1021/nn202451x.

(3) Mayerberger, E. A.; Street, R. M.; McDaniel, R. M.; Barsoum, M. W.; Schauer, C. L. Antibacterial properties of electrospun Ti3C2Tz (MXene)/chitosan nanofibers. RSC Advances 2018, 8 (62), 3538635394, DOI: 10.1039/c8ra06274a.

(4) Alimohammadi, F.; Sharifian Gh, M.; Attanayake, N. H.; Thenuwara, A. C.; Gogotsi, Y.; Anasori, B.; Strongin, D. R. Antimicrobial Properties of 2D MnO2 and MoS2 Nanomaterials Vertically Aligned on Graphene Materials and Ti3C2 MXene. Langmuir 2018, 34 (24), 7192-7200, DOI:

10.1021/acs.langmuir.8b00262.

(5) Jastrzębska, A. Biological Activity and Bio-Sorption Properties of the Ti2C Studied by Means of Zeta Potential and SEM. International Journal of Electrochemical Science 2017, 2159-2172, DOI: 10.20964/2017.03.06.

(6) Pandey, R. P.; Rasool, K.; Madhavan, V. E.; Aïssa, B.; Gogotsi, Y.; Mahmoud, K. A. Ultrahigh-flux and fouling-resistant membranes based on layered silver/MXene (Ti3C2Tx) nanosheets. Journal of Materials Chemistry A 2018, 6 (8), 3522-3533, DOI: 10.1039/C7TA10888E. 